\title{
Bare metal stents, durable polymer drug eluting stents, and biodegradable polymer drug eluting stents for coronary artery disease: mixed treatment comparison meta-analysis
}

Sripal Bangalore director of research, assistant professor of medicine ${ }^{1}$, Bora Toklu assistant professor of medicine ${ }^{2}$, Nicholas Amoroso fellow in cardiovascular medicine ${ }^{1}$, Mario Fusaro fellow in critical care $^{1}$, Sunil Kumar fellow in cardiovascular medicine ${ }^{5}$, Edward L Hannan distinguished professor emeritus of health policy, management and behavior ${ }^{3}$, David P Faxon professor of medicine ${ }^{4}$, Frederick Feit professor of medicine ${ }^{1}$

${ }^{1}$ New York University School of Medicine, The Leon H Charney Division of Cardiology, New York, NY 10016, USA; ${ }^{2}$ Virginia Commonwealth University, Richmond, VA, USA; ${ }^{3}$ School of Public Health, The University at Albany, Albany, NY, USA; ${ }^{4}$ Brigham and Women's Hospital, Boston, MA, USA; ${ }^{5}$ University of Nebraska, Omaha, Nebraska, NE

\begin{abstract}
Objective To compare the efficacy and safety of biodegradable polymer drug eluting stents with those of bare metal stents and durable polymer drug eluting stents.

Design Mixed treatment comparison meta-analysis of 258544 patient years of follow-up from randomized trials.

Data sources and study selection PubMed, Embase, and Central were searched for randomized trials comparing any of the Food and Drug Administration approved durable polymer drug eluting stents (sirolimus eluting, paclitaxel eluting, cobalt chromium everolimus eluting, platinum chromium everolimus eluting, zotarolimus eluting-Endeavor, and zotarolimus eluting-Resolute) or biodegradable polymer drug eluting stents, with each other or against bare metal stents.

Outcomes Long term efficacy (target vessel revascularization, target lesion revascularization) and safety (death, myocardial infarction, stent thrombosis). Landmark analysis at more than one year was evaluated to assess the potential late benefit of biodegradable polymer drug eluting stents.

Results From 126 randomized trials and 258544 patient years of follow-up, for long term efficacy (target vessel revascularization), biodegradable polymer drug eluting stents were superior to paclitaxel eluting stents (rate ratio $0.66,95 \%$ credibility interval 0.57 to 0.78 ) and zotarolimus eluting stent-Endeavor $(0.69,0.56$ to 0.84$)$ but not to newer generation durable polymer drug eluting stents (for example: 1.03, 0.89 to 1.21 versus cobalt chromium everolimus eluting stents). Similarly,
\end{abstract}

biodegradable polymer drug eluting stents were superior to paclitaxel eluting stents (rate ratio $0.61,0.37$ to 0.89 ) but inferior to cobalt chromium everolimus eluting stents $(2.04,1.27$ to 3.35$)$ for long term safety (definite stent thrombosis). In the landmark analysis after one year, biodegradable polymer drug eluting stents were superior to sirolimus eluting stents for definite stent thrombosis (rate ratio $0.29,0.10$ to 0.82 ) but were associated with increased mortality compared with cobalt chromium everolimus eluting stents (1.52, 1.02 to 2.22). Overall, among all stent types, the newer generation durable polymer drug eluting stents (zotarolimus eluting stent-Resolute, cobalt chromium everolimus eluting stents, and platinum chromium everolimus eluting stents) were the most efficacious (lowest target vessel revascularization rate) stents, and cobalt chromium everolimus eluting stents were the safest with significant reductions in definite stent thrombosis (rate ratio $0.35,0.21$ to 0.53 ), myocardial infarction $(0.65,0.55$ to 0.75$)$, and death $(0.72,0.58$ to 0.90$)$ compared with bare metal stents.

Conclusions Biodegradable polymer drug eluting stents are superior to first generation durable polymer drug eluting stents but not to newer generation durable polymer stents in reducing target vessel revascularization. Newer generation durable polymer stents, and especially cobalt chromium everolimus eluting stents, have the best combination of efficacy and safety. The utility of biodegradable polymer stents in the context of excellent clinical outcomes with newer generation durable polymer stents needs to be proven. 


\section{Introduction}

Drug eluting stents with durable polymer coatings significantly reduce late lumen loss and consequently reduce rates of target lesion and target vessel revascularization compared with bare metal stents and have revolutionized the practice of percutaneous coronary intervention. ${ }^{1}$ However, first generation durable polymer drug eluting stents have been associated with an increased risk of very late stent thrombosis compared with bare metal stents, especially in high risk patient populations..$^{2-4}$ This increased risk has been attributed, in part, to hypersensitivity reactions to the polymer resulting in inflammation, late stent malapposition, and stent thrombosis. Consequently, durable polymer stents have been considered the benchmark for efficacy (restenosis), whereas bare metal stents have been considered the benchmark for safety (stent thrombosis). Biodegradable polymer drug eluting stents, in which the polymer coating biodegrades over two to nine months, were developed to provide similar long term safety to bare metal stents while maintaining the early efficacy of durable polymer drug eluting stents.

However, newer generation durable polymer stents, especially cobalt chromium everolimus eluting stents, have been shown to reduce the risk of stent thrombosis compared with bare metal stents, challenging this traditional benchmark for safety. ${ }^{1}$ In the EXAMINATION trial, cobalt chromium everolimus eluting stents were associated with a reduction in the risk of definite stent thrombosis at both one year and two year follow-up. ${ }^{56}$ Whether biodegradable polymer stents would be either better or safer than newer generation durable polymer stents is therefore unknown. Therefore, our objective was to compare the efficacy and safety of biodegradable polymer drug eluting stents with those of bare metal stents and durable polymer drug eluting stents.

\section{Methods}

\section{Study search and eligibility criteria}

We did a systematic search, without language restriction, for randomized clinical trials of bare metal stents, durable polymer drug eluting stents, or biodegradable polymer drug eluting stents by using MeSH terms (supplementary table D) and the names of individual Food and Drug Administration approved durable polymer stent systems (sirolimus eluting stent, paclitaxel eluting stent, cobalt chromium everolimus eluting stent, platinum chromium everolimus eluting stent, zotarolimus eluting stent-Endeavor, and zotarolimus eluting stent-Resolute), as well as biodegradable polymer drug eluting stents, until May 2013 (week 3). None of the biodegradable polymer stents is FDA approved. We searched the following databases and sources: PubMed, Embase, the Cochrane Central Register of Controlled Trials, Google Scholar, and conference proceedings/abstracts of the Transcatheter Cardiovascular Therapeutics, Euro-PCR, Society of Cardiovascular Angiography and Intervention, American College of Cardiology, American Heart Association, and European Society of Cardiology. We checked the reference lists of original trial reports, review articles, and meta-analyses to find other eligible trials. For studies that did not report outcomes of interest, we contacted the authors by email. We kept the review updated by using automated weekly email alerts. The search process was fairly extensive, and efforts were made to obtain the longest reported follow-up data from a combination of sources: all the published data, previous meta-analyses, presentations at national meetings, and unpublished data from communication with authors.
We included trials comparing the above stent categories in patients having percutaneous coronary intervention, enrolling at least 50 patients with follow-up of at least six months, and reporting the outcomes of interest (see below). We excluded trials that used biodegradable scaffolds or non-polymer drug eluting stents; trials of biodegradable polymer drug eluting stents that are no longer in production (such as the Nevo stent, CoStar stent, and ProStent); trials of durable polymer stents with an eluting drug other than the six listed above; and trials comparing bare metal stents with non-durable polymer/biodegradable polymer drug eluting stents, drug eluting balloons, or balloon angioplasty alone or with coronary artery bypass graft surgery. The characteristics of the biodegradable polymer and durable polymer stents, including the stent material, polymer coating, and drug eluted, along with the polymer degradation kinetics, are summarized in supplementary table E.

\section{Selection and quality assessment}

Five authors (SB, BT, SK, MF, and NA) independently assessed trials' eligibility and risk of bias and extracted data.

Disagreements were resolved by discussion and consensus. The bias risks of trials were assessed by using the components recommended by the Cochrane Collaboration ${ }^{7}$ : sequence generation; allocation concealment; blinding of participants, personnel, and outcome assessors (with blinding of at least the outcome assessors required for considering this parameter as low risk of bias); incomplete outcome data; selective outcome reporting; and other sources of bias. We considered trials with high or unclear risk of bias for any one of the first three components as being at high risk of bias. We considered all other trials as being at low risk of bias.

\section{Efficacy and safety outcomes}

Efficacy outcomes were target vessel revascularization (primary) and target lesion revascularization (secondary). Safety outcomes were death, myocardial infarction, and stent thrombosis. Three types of stent thrombosis were evaluated: Academic Research Consortium (ARC) defined definite stent thrombosis (primary), ARC defined "definite" or "probable" stent thrombosis, and "any" stent thrombosis (on the basis of the trial definition of stent thrombosis) (secondary). ${ }^{8}$ Table $1 \Downarrow$ summarizes the standard definitions of the outcomes evaluated.

We did primary analyses for each outcome at the longest available follow-up time point. Given the theoretical benefit of the biodegradable polymer drug eluting stents after the polymer is absorbed (within first two to nine months), we did a landmark analysis to evaluate for late events, defined as events beyond the first year. For this analysis, events within the first year after stent implantation were censored.

\section{Statistical analyses Mixed treatment comparisons}

For the purpose of this analysis, we defined eight stent types: bare metal stent, sirolimus eluting stent, paclitaxel eluting stent, cobalt chromium everolimus eluting stent, platinum chromium everolimus eluting stent, zotarolimus eluting stent-Endeavor, zotarolimus eluting stent-Resolute, and biodegradable polymer drug eluting stent. We did analyses for each individual pair of stent comparisons. We used Bayesian mixed treatment comparison models to compare the different stent types by using WinBUGS 1.4.3 (MRC Biostatistics Unit, Cambridge, UK). ${ }^{9}$ The network of all the trials contained direct comparison between two stent types as well as stent types for which no direct comparison between the stent types was available. Mixed 
treatment comparison allows for comparisons of stents not directly compared in any of the individual trials by incorporating the indirect comparisons constructed from two trials that have one stent type in common (such as comparison of stent A versus $\mathrm{C}$ by using trials comparing $\mathrm{A}$ versus $\mathrm{B}$ and $\mathrm{B}$ versus $\mathrm{C}$ ).

Given the variability in the length of follow-up for each of these trials, we used the rate of outcomes per 100 person years to obtain the $\log$ rate ratios of one stent relative to another, thereby incorporating the duration of the trials. We used a random effects Poisson regression model to do the analysis after taking into account the correlation structure induced by the multi-arm trials. ${ }^{10}$ We used a random effects rather than a fixed effect model because this is likely the most appropriate and conservative analysis to account for both within study and between study variance. However, we also constructed a fixed effect model in a sensitivity analysis to evaluate the consistency of the results. We assessed convergence by using a burn-in phase of 50000 simulations, and we used a further 100000 simulations for the final analyses. We estimated rate ratios from the median, and the accompanying $95 \%$ credibility intervals came from the 2.5 th and 97.5th centiles of the posterior distribution. We also calculated the probability that a given stent is associated with the lowest event proportion for a particular outcome by using a Bayesian Markov Chain Monte Carlo method, adapted to apply to a connected network set of treatment comparisons. We used minimally informative prior distributions for log rate ratios $(-10,10)$ and for random effects standard deviations $(0,2)$, so the findings should be close to those obtained with frequentist methods.

\section{Heterogeneity and goodness of fit}

We evaluated the validity of the network model by assessing three important characteristics of the model: between trial heterogeneity, goodness of fit, and consistency. We evaluated heterogeneity $\left(\tau^{2}\right)$, defined as the variability of results across trials over and above chance, for the mixed treatment comparison analysis on the basis of the methods described previously. ${ }^{11}$ We interpreted an $\tau^{2}$ estimate of 0.04 as a low degree, 0.14 as a moderate degree, and 0.40 as a high degree of heterogeneity. We considered the model to provide an adequate fit to the data if the mean of the residual deviance was similar to the number of data points used in the model, at least $95 \%$ of means of standardized node based residuals were within \pm 1.96 of the standard normal deviations, and Q-Q plots of residuals fell closely around a line on visual inspection. ${ }^{11}$ In addition, we evaluated the inconsistency of the network, defined as the variability of results across different comparisons of the network, by comparing the estimates from the network analysis with the rate ratio obtained from the direct comparison meta-analysis.

\section{Direct comparison meta-analysis}

We did intention to treat direct comparison meta-analysis in line with recommendations from the Preferred Reporting Items for Systematic Reviews and Meta-Analyses (PRISMA) statement, ${ }^{72}$ using standard software (Stata 9.0). ${ }^{13}$ We assessed heterogeneity by using the $\mathrm{I}^{2}$ statistic, ${ }^{14}$ considering $\mathrm{I}^{2}<25 \%$ to be low and $\mathrm{I}^{2}>5 \%$ high. We used the random effects model of DerSimonian and Laird to calculate rate ratios. ${ }^{15}$ We estimated publication bias by using Begg's test and the weighted regression test of Egger, as well as visually with funnel plots. ${ }^{16}$

\section{Sensitivity analysis}

We planned a sensitivity analysis to assess for the robustness and consistency of the primary analysis by restricting analysis to trials with a low risk of bias. We considered doing a further sensitivity analysis restricted to trials in which no routine angiographic follow-up was done, as routine angiographic follow-up has been shown to increase the rate of repeat revascularization (occulostenotic reflex). However, we rejected this as most of the biodegradable polymer stent trials had routine angiographic follow-up and this sensitivity analysis would have excluded most of these stents. We considered a further sensitivity analysis restricting trials to those that enrolled only patients without acute coronary syndrome, but we rejected this as most of the biodegradable polymer stent trials enrolled patients with and without acute coronary syndrome. Of note, the above two sensitivity analyses were done in our previous publication and have shown consistency in the results and robustness of the conclusions. ${ }^{117}$ Finally, we did a sensitivity analysis in which each biodegradable polymer stent was considered as a separate stent in itself.

\section{Results}

\section{Study selection and characteristics of included trials}

Our search strategy yielded 126 randomized trials (fig $1 \Downarrow$ ) that enrolled 106427 patients, followed for a mean of 2.3 (range 0.5-5) years, for a total of 258544 patient years of follow-up. Twenty eight trials randomized patients to a biodegradable polymer drug eluting stent, and the rest used durable polymer drug eluting stents. Figure $2 \Downarrow$ shows the network of stent comparisons. One trial was a four arm trial, nine trials had three arms, and the rest had two arms (supplementary table A). Most trials $(106 ; 87 \%)$ used clopidogrel for at least six months in the durable polymer/biodegradable polymer drug eluting stent arms, and 81 trials were considered at low risk of bias (supplementary table B). In the trials of biodegradable polymer drug eluting stents, most (24/28 trials) used clopidogrel for at least six months in the biodegradable polymer stent group, whereas this information was not reported in the remaining four trials (supplementary table B). Supplementary table E outlines the type of biodegradable polymer stents used and the absorption kinetics.

\section{Efficacy outcomes: target vessel/lesion revascularization}

Compared with bare metal stents (reference rate ratio of 1), sirolimus eluting stents (number needed to treat (NNT) 22.4, 95\% confidence interval 21.3 to 23.9 ), paclitaxel eluting stents (32.3, 31.9 to 33.4), cobalt chromium everolimus eluting stents (20.6, 19.9 to 21.3$)$, platinum chromium everolimus eluting stents $(19.5,18.7$ to 22.1$)$, zotarolimus eluting stent-Endeavor (30.1, 29.9 to 32.6), zotarolimus eluting stent-Resolute (20.0, 19.4 to 21.1 ), and biodegradable polymer drug eluting stents (20.9, 21.6 to 20.7) were all associated with a significant reduction in the rate of target vessel revascularization (fig $3 \Downarrow$ ) (table $2 \Downarrow$ ). Biodegradable polymer drug eluting stents were associated with a significant reduction in the risk of target vessel revascularization compared with bare metal stents (59\% reduction), paclitaxel eluting stents (34\% reduction), and zotarolimus eluting stent-Endeavor (31\% reduction) but were similar compared with the other durable polymer drug eluting stents (fig $3 \Downarrow$ ). Other pairwise stent comparisons are shown in figure $3 \Downarrow$.

Probability analysis showed that platinum chromium everolimus eluting stents ( $50 \%$ probability), zotarolimus eluting stent-Resolute ( $30 \%$ probability), cobalt chromium everolimus eluting stents ( $9 \%$ probability), and biodegradable polymer drug 
eluting stents (9\% probability) were associated with the lowest target vessel revascularization rate (table $2 \Downarrow$ ). Of note, the between stent comparisons for every pair of the above stent comparisons were not significant, suggesting similar efficacy of these four stent types. Results were similar when restricted to trials with a low risk of bias (supplementary tables F and G), in the direct comparison meta-analysis (supplementary table $\mathrm{M}$ ), and also for target lesion revascularization (supplementary table $\mathrm{G}$ and figure $\mathrm{A}$ ).

We found low heterogeneity both for the overall analyses $\left(\tau^{2}=0.01\right)$ and for the analysis restricted to trials at low risk of bias $\left(\tau^{2}=0.02\right)$ (supplementary table I). In addition, evaluation of the goodness of fit showed adequate fit (supplementary tables $\mathrm{J}$ and $\mathrm{K})$.

\section{Safety outcomes: death/myocardial infarction/stent thrombosis}

Cobalt chromium everolimus eluting stents were associated with a $28 \%$ reduction in the rate of death (NNT $=169,168$ to 185) compared with bare metal stents, with no difference for other stent comparators (fig $4 \Downarrow$ ) (table $2 \Downarrow$ ). Biodegradable polymer drug eluting stents were not associated with any significant reduction in death compared with other stents (fig 4). The other pairwise stent comparisons are shown in figure $4 \Downarrow$. We found no significant differences between any combination of durable polymer or biodegradable polymer drug eluting stents for the outcome of death, although a strong trend existed towards reduction in death with cobalt chromium everolimus eluting stents compared with paclitaxel eluting stents (rate ratio $0.81,0.66$ to 1.00 ). Probability analysis showed that cobalt chromium everolimus eluting stents, platinum chromium everolimus eluting stents, and zotarolimus eluting stent-Resolute were associated with the lowest death rate (table $2 \Downarrow$ ). The fact that none of the between stent comparisons for these three stent types was significant suggests that they all have similar safety. Results were largely similar in a sensitivity analysis restricted to trials at low risk of bias (supplementary tables $\mathrm{F}$ and $\mathrm{H}$ ) and in the direct comparison meta-analysis (supplementary table $\mathrm{M})$.

For the outcome of myocardial infarction, sirolimus eluting stents (NNT 312, 263 to 357), cobalt chromium everolimus eluting stents $(151,133$ to 172$)$, platinum chromium everolimus eluting stents (137, 133 to 172), zotarolimus eluting stent-Endeavor (278, 278 to 278$)$, zotarolimus eluting stent-Resolute $(185,178$ to 227$)$, and biodegradable polymer drug eluting stents (270, 263 to 270) were associated with significant reductions compared with bare metal stents, but no reduction was seen for paclitaxel eluting stents (fig $5 \Downarrow$ ) (table $2 \Downarrow$ ). Biodegradable polymer drug eluting stents were associated with a lower rate of myocardial infarction compared with bare metal stents or paclitaxel eluting stents but a higher rate than with cobalt chromium everolimus eluting stents (fig $5 \Downarrow$ ). The other pairs of stent comparisons are shown in figure $5 \Downarrow$.

Probability analysis showed that cobalt chromium everolimus eluting stents ( $29 \%$ probability), platinum chromium everolimus eluting stents ( $56 \%$ probability), and zotarolimus eluting stent-Resolute (12\% probability) were associated with the lowest myocardial infarction rate (table $2 \Downarrow$ ). The between stent comparisons for these three stent types were not significant, suggesting probably similar safety for avoidance of myocardial infarction. Results were largely similar in a sensitivity analysis restricted to trials at low risk of bias (supplementary table $\mathrm{F}$ and figure B) and in the direct comparison meta-analysis (data not shown).
For the outcome of ARC definite stent thrombosis, when compared with bare metal stents, only cobalt chromium everolimus eluting stents (NNT 384, 278 to 555) were associated with a significant reduction (fig $6 \Downarrow$; table $2 \Downarrow$ ). Biodegradable polymer drug eluting stents were associated with a lower rate of definite stent thrombosis compared with paclitaxel eluting stents (49\% reduction), with a trend towards a reduction compared with sirolimus eluting stents (rate ratio $0.71,0.49$ to 1.01 ) but a higher rate compared with cobalt chromium everolimus eluting stents (fig $6 \Downarrow$ ). The other pairs of stent comparisons are shown in figure $6 \downarrow$. Probability analysis showed that cobalt chromium everolimus eluting stents $(81 \%$ probability) were associated with the lowest rate of definite stent thrombosis (table $2 \Downarrow$ ). Results were largely similar in a sensitivity analysis restricted to trials at low risk of bias (supplementary tables $\mathrm{F}$ and $\mathrm{H}$ ), in the direct comparison meta-analysis (supplementary table M), for the outcome of ARC definite or probable stent thrombosis (supplementary figure C), and for the outcome of "any" stent thrombosis (supplementary figure D). We found low heterogeneity and adequate fit for the above analyses (supplementary tables I-K).

\section{Late events: landmark analysis beyond one year}

In a landmark analysis evaluating events after one year, biodegradable polymer drug eluting stents were associated with a reduction in the risk of target vessel revascularization compared with bare metal stents (33\% reduction) but not compared with durable polymer drug eluting stents (table $3 \Downarrow$; fig $7 \Downarrow$ ). Similarly, for the outcome of death, biodegradable polymer stents were not associated with any significant reduction compared with bare metal stents but were associated with an increased risk compared with cobalt chromium everolimus eluting stents ( $52 \%$ increase) (table $3 \Downarrow$; fig $8 \Downarrow$ ). For the outcome of myocardial infarction, biodegradable polymer stents were not associated with any significant reduction compared with bare metal stents or durable polymer stents, but the point estimate favored biodegradable polymer stents compared with first generation durable polymer stents (table $3 \Downarrow$; fig $9 \Downarrow$ ). For definite stent thrombosis, biodegradable polymer stents were not associated with any significant reduction compared with bare metal stents but were associated with a reduction in risk compared with sirolimus eluting stents ( $71 \%$ reduction), with no difference for the rest of the pairwise comparisons (table $3 \Downarrow$; fig $10 \Downarrow$ ) or for other outcomes (table $3 \Downarrow$; figures $7 \Downarrow, 8 \Downarrow,[9 \Downarrow$ and $10 \Downarrow$; supplementary figures 3 and 4 ). The other pairwise stent comparisons are shown in figures $7 \Downarrow, 8 \Downarrow,[9 \Downarrow$ and $10 \Downarrow$. Results were largely similar in the sensitivity analysis restricted to trials at low risk of bias (supplementary table L). We found low heterogeneity with adequate fit for the above analyses (supplementary tables I-K).

Sensitivity analysis based on each individual biodegradable polymer drug eluting stent showed that no one type of stent was clearly superior to the other (supplementary table N). However, this is an exploratory analysis with imprecise estimates and wide credibility intervals.

\section{Discussion}

The results of this study, with data derived from 126 randomized trials and more than a quarter million patient years of follow-up, showed that biodegradable polymer drug eluting stents are not superior to newer generation durable polymer drug eluting stents for either efficacy or safety outcomes. Newer generation durable polymer stents (cobalt chromium everolimus eluting stents, 
platinum chromium everolimus eluting stents, and zotarolimus eluting stent-Resolute) were the most effective stents in having the lowest rate of repeat revascularization, no increase in very late stent thrombosis, and a significant decrease in the risk of myocardial infarction. Furthermore, a decrease in definite stent thrombosis, myocardial infarction, and death were seen when cobalt chromium everolimus eluting stents were compared with bare metal stents.

\section{Biodegradable polymer drug eluting stents}

The first generation durable polymer drug eluting stents, such as the sirolimus eluting and paclitaxel eluting stents, although they significantly reduce restenosis compared with bare metal stents, ${ }^{18-20}$ have disadvantages. They are associated with an increased risk of very late stent thrombosis, ${ }^{2-4}$ and hence a need for extended dual antiplatelet treatment to reduce this risk of very late stent thrombosis. ${ }^{21} 22$

Several mechanisms have been implicated in the various drawbacks of the first generation stents, including thicker stent struts and hypersensitivity reaction to the polymer (due to non-uniform coating of the polymer, webbing and bonding of the polymer surface, and polymer delamination) leading to inflammation, delayed healing, late stent malapposition, restenosis, and thrombosis. ${ }^{23}$ Biodegradable polymer drug eluting stents offer an attractive option preserving the efficacy of durable polymer stents and offering the safety of bare metal stents when the polymer is absorbed leaving behind a bare metal stent. In a pooled analysis of patient level data from the ISAR-TEST 3, ISAR-TEST 4, and LEADERS trials, at four years,

biodegradable polymer stents were associated with significant reductions of target lesion revascularization (hazard ratio, 95\% confidence interval 0.68 to $0.98 ; \mathrm{P}=0.029)$ and stent thrombosis $(0.56,0.35$ to $0.90 ; \mathrm{P}=0.015)$, driven by a decrease in very late stent thrombosis $(0.22,0.08$ to $0.61 ; \mathrm{P}=0.004)$ and a decrease in myocardial infarction between one and four years, when compared with sirolimus eluting stents. ${ }^{24}$

However, it is not known if this superiority of biodegradable polymer drug eluting stents over first generation durable polymer stents is applicable to the newer generation durable polymer stents, which have thinner stent struts (Xience V versus Cypher: $81 \mu \mathrm{m} v 140 \mu \mathrm{m}$ ) and thinner polymer (Xience V versus Cypher: $7.8 \mu \mathrm{m} v 13.7 \mu \mathrm{m}$ ) with more uniform coating with less webbing and bonding of the polymer surface, less polymer delamination, and more biocompatibility. We have shown, in an analysis of 76 randomized trials with 117762 patient years of follow-up, that cobalt chromium everolimus eluting stents were associated with a significant reduction in stent thrombosis compared with bare metal stents (rate ratio $0.51,95 \%$ credibility interval 0.35 to 0.73 ). ${ }^{1}$ Lower rates of stent thrombosis with cobalt chromium everolimus eluting stents were seen in the Bern-Rotterdam cohort study (compared with other durable polymer stents), in the Swedish Coronary Angiography and Angioplasty Registry (SCAAR) (compared with bare metal stents), ${ }^{25}$ and in the EXAMINATION trial (compared with bare metal stents) at one year $(0.5 \% \vee 1.9 \% ; \mathrm{P}=0.019)$ and two years $(0.8 \% \vee 2.1 \%$; $\mathrm{P}=0.03) .^{56}$

In the light of the above data, whether bare metal stents should continue to be the benchmark for safety is not clear, thereby further questioning the biodegradable polymer drug eluting stents hypothesis. The results of the study reported here suggest no advantage of biodegradable polymer stents compared with newer generation durable polymer stents. Similarly to data from Stefanini et al, ${ }^{24}$ biodegradable polymer drug eluting stents were associated with a reduction in the risk of target vessel revascularization (versus bare metal stents, paclitaxel eluting stents, and zotarolimus eluting stent-Endeavor), definite stent thrombosis (versus paclitaxel eluting stents and sirolimus eluting stents), and myocardial infarction (versus bare metal stents and paclitaxel eluting stents) when compared with bare metal stents or first generation durable polymer drug eluting stents. In a landmark analysis evaluating events after one year, we saw a trend towards reductions in myocardial infarction (versus sirolimus eluting stents: $0.69,0.49$ to 1.09 ; versus paclitaxel eluting stents: $0.63,0.39$ to 1.13 ), definite stent thrombosis (versus sirolimus eluting stents: $0.29,0.10$ to 0.82 ), and any stent thrombosis (versus paclitaxel eluting stents: $0.34,0.15$ to 0.84 ), consistent with previously published data. ${ }^{24}$ However, when compared with newer generation durable polymer stents, we saw no reduction in the risk of any outcomes. In fact, compared with cobalt chromium everolimus eluting stents, biodegradable polymer drug eluting stents were associated with increase in myocardial infarction and death beyond the one year landmark point, which was attenuated in a sensitivity analysis restricted to trials at low risk of bias (rate ratio 1.48, 0.96 to 2.09).

The current trials of biodegradable polymer drug eluting stents have been designed with the aim of showing non-inferiority to durable polymer drug eluting stents (supplementary table C). This is acceptable as long as this platform has additional advantages such as lower cost and reduced need for dual antiplatelet treatment. However, the need for dual antiplatelet treatment would be unlikely to be less than six months for biodegradable polymer stents on the basis of the current trial designs, in which the minimum requirement has been six months. Moreover, use of dual antiplatelet treatment beyond the first year is uncommon with newer generation durable polymer stents; less than $20 \%$ of patients continued treatment at two years in the EXAMINATION trial, ${ }^{6}$ and trials are now evaluating even shorter duration of treatment than the traditional 12 months.$^{26}$ Consequently, regulatory approval has now been given to update the $\mathrm{CE}$ (Conformité Européenne) mark labeling for one month of dual antiplatelet treatment for the zotarolimus eluting stent-Resolute and three months for the cobalt chromium everolimus eluting stent in Europe. The biodegradable polymer drug eluting stents will therefore be unlikely to have a shorter duration of dual antiplatelet treatment than the newer generation durable polymer drug eluting stents. In the light of the above, large randomized trials designed to show the superiority of biodegradable polymer stents over newer generation durable polymer stents and especially over cobalt chromium everolimus eluting stents are needed before their role in the treatment of patients with coronary artery disease can be firmly established.

\section{Durable polymer drug eluting stents}

This study extends our previous observation, ${ }^{1}$ in that 50 more trials were added with a total of more than 250000 patient years of follow-up; since the previous publication, many trials that were included previously have now reported longer term follow-up and the results have been updated; we included platinum chromium everolimus eluting stents as a separate category; and biodegradable polymer drug eluting stents were included. The findings are largely similar in that among the durable polymer drug eluting stents, zotarolimus eluting stent-Resolute, cobalt chromium everolimus eluting stents, and platinum chromium everolimus eluting stents were the most efficacious but cobalt chromium everolimus eluting stents continue to have the lowest stent thrombosis rate. Of note, although platinum chromium everolimus eluting stents have been associated with an increased risk of longitudinal stent 
deformation, ${ }^{27}$ the results from randomized clinical trials suggest similar efficacy and safety compared with leading newer generation durable polymer stents. In addition, cobalt chromium everolimus eluting stents reduced the risk of death compared with bare metal stents, similar to the observation from the recent pooled analysis of the SPIRIT trials (versus paclitaxel eluting stents) showing a reduction in death and death/myocardial infarction with this stent type. The reduction in death or myocardial infarction with newer generation stents is not surprising, as both restenosis and stent thrombosis, which are significantly reduced by newer generation durable polymer stents, are associated with a significant increase in the risk of death and myocardial infarction.

\section{Limitations of study}

As in previous analyses, the study combines trial level data only. However, the validity of the network model was thoroughly tested, and the model satisfied the three basic requirements of a network model: low to moderate heterogeneity of the trials, adequate fit of the model, and consistency with direct comparison analysis. We did not control for the duration of dual antiplatelet treatment, and analysis was not done on the basis of duration of dual antiplatelet treatment as most of the trials of biodegradable polymer stents used such treatment for at least six months. In our previous analysis, the study results were concordant on the basis of several sensitivity analyses, including analysis based on duration of dual antiplatelet treatment, whether or not routine angiographic follow-up was done, and trials limited to patients without acute coronary syndrome.

The sensitivity analyses based on individual biodegradable polymer drug eluting stents has several limitations. The total number of distinct stent type with this approach is 24 , resulting in 276 unique pairwise comparisons. No head to head comparison of any two biodegradable polymer drug eluting stents was available, so all estimates are based on indirect comparison only. The sample size for individual biodegradable polymer drug eluting stents was several times lower than for the comparator, resulting in wide credibility intervals and imprecise estimates. Nevertheless, combining all of the biodegradable polymer drug eluting stents into a single class may be reasonable, as the proposed benefit of these stents are for late events when the polymer has degraded and a bare metal stent-like stent is left over. Future randomized trials are needed to evaluate whether any one biodegradable polymer drug eluting stent is superior to another.

\section{Conclusions}

In this study, the largest series so far with data from more than a quarter million patient years of follow-up, biodegradable polymer drug eluting stents were not associated with any reduction in the risk of adverse clinical outcomes compared with newer generation durable polymer drug eluting stents. Zotarolimus eluting stent-Resolute, platinum chromium everolimus eluting stents, and cobalt chromium everolimus eluting stents were the most efficacious stents for reducing the risk of target vessel revascularization. Cobalt chromium everolimus eluting stents were the safest stent, with a significantly reduced risk of stent thrombosis, death, and myocardial infarction compared with bare metal stents; significant reduction in define stent thrombosis rate and risk of death after one year when compared with biodegradable polymer drug eluting stents; and no increase in very late stent thrombosis.
Contributors: SB was responsible for the study concept and design. SB, $\mathrm{BT}, \mathrm{SK}, \mathrm{MF}$, and NA were involved in acquisition of data. SB was responsible for analysis and interpretation of data. SM and NT drafted the manuscript. All authors critically revised the manuscript for important intellectual content. SB supervised the study and is the guarantor.

Funding: This research received no specific grant from any funding agency in the public, commercial, or not for profit sectors.

Competing interests: All authors have completed the ICMJE uniform disclosure form at www.icmje.org/coi_disclosure.pdf (available on request from the corresponding author) and declare: no support from any organisation for the submitted work; SB has acted as an advisory board participant/consultant for Boehringer Ingelheim, Daiichi Sankyo, Pfizer, Gilead, Abbott, and Abbott-Vascular; FF is a shareholder in Medtronic, Boston Scientific, and Johnson and Johnson; no other relationships or activities that could appear to have influenced the submitted work.

\section{Ethical approval: Not required.}

Data sharing: No additional data available.

Declaration of transparency: The lead author (the manuscript's guarantor) affirms that the manuscript is an honest, accurate, and transparent account of the study being reported; no important aspects of the study have been omitted; and any discrepancies from the study as planned (and, if relevant, registered) have been explained.

1 Bangalore S, Kumar S, Fusaro M, Amoroso N, Attubato MJ, Feit F, et al. Short- and long-term outcomes with drug-eluting and bare-metal coronary stents: a mixed-treatment comparison analysis of 117762 patient-years of follow-up from randomized trials. Circulation 2012;125:2873-91.

2 Raber L, Magro M, Stefanini GG, Kalesan B, van Domburg RT, Onuma Y, et al. Very late coronary stent thrombosis of a newer-generation everolimus-eluting stent compared with early-generation drug-eluting stents: a prospective cohort study. Circulation 2012;125:1110-21.

3 De Luca G, Dirksen MT, Spaulding C, Kelbaek H, Schalij M, Thuesen L, et al. Drug-eluting vs bare-metal stents in primary angioplasty: a pooled patient-level meta-analysis of randomized trials. Arch Intern Med 2012;172:611-21; discussion 21-2.

4 Lagerqvist B, James SK, Stenestrand U, Lindbäck J, Nilsson T, Wallentin L. Long-term outcomes with drug-eluting stents versus bare-metal stents in Sweden. N Engl J Med 2007:356:1009-19.

5 Sabate M, Cequier A, Iniguez A, Serra A, Hernandez-Antolin R, Mainar V, et al. Everolimus-eluting stent versus bare-metal stent in ST-segment elevation myocardial infarction (EXAMINATION): 1 year results of a randomised controlled trial. Lancet 2012;380:1482-90.

6 Sabate M. EXAMINATION 2-year: a prospective, randomized trial of everolimus-eluting vs. bare metal stents in patients with ST-segment elevation myocardial infarction. 2012. www.tctmd.com/show. aspx?id=114393.

7 Higgins J, Green S. Cochrane handbook for systematic reviews of interventions. Version 5.0.0. Cochrane Collaboration, 2008.

8 Cutlip DE, Windecker S, Mehran R, Boam A, Cohen DJ, van Es GA, et al. Clinical end points in coronary stent trials: a case for standardized definitions. Circulation 2007;115:2344-51

9 Caldwell DM, Ades AE, Higgins JP. Simultaneous comparison of multiple treatments: combining direct and indirect evidence. BMJ 2005;331:897-900.

10 Spiegelhalter D, Abrams K, Myles J. Bayesian approaches to clinical trials and health-care evaluation. statistics in practice. John Wiley and Sons, 2004.

11 Stettler C, Allemann S, Wandel S, Kastrati A, Morice MC, Schomig A, et al. Drug eluting and bare metal stents in people with and without diabetes: collaborative network meta-analysis. BMJ 2008:337:a1331.

12 Moher D, Cook DJ, Eastwood S, Olkin I, Rennie D, Stroup DF. Improving the quality of reports of meta-analyses of randomised controlled trials: the QUOROM statement. Lancet 1999;354:1896-900.

13 Bradburn MJ, Deeks JJ, Altman DG. Sbe24: metan-an alternative meta-analysis command. Stata Technical Bulletin Reprints 1998;8:86-100.

14 Law M. Outcome measurement in pediatric rehabilitation. Phys Occup Ther Pediatr 2003;23:1-4.

15 DerSimonian R, Laird N. Meta-analysis in clinical trials. Control Clin Trials 1986;7:177-88.

16 Egger M, Davey Smith G, Schneider M, Minder C. Bias in meta-analysis detected by a simple, graphical test. BMJ 1997;315:629-34.

17 Bangalore S, Kumar S, Fusaro M, Amoroso N, Kirtane AJ, Byrne RA, et al. Outcomes with various drug eluting or bare metal stents in patients with diabetes mellitus: mixed treatment comparison analysis of 22844 patient years of follow-up from randomised trials. BMJ 2012;345:e5170.

18 Moses JW, Leon MB, Popma JJ, Fitzgerald PJ, Holmes DR, O'Shaughnessy C, et al. Sirolimus-eluting stents versus standard stents in patients with stenosis in a native coronary artery. N Engl J Med 2003;349:1315-23.

19 Colombo A, Drzewiecki J, Banning A, Grube E, Hauptmann K, Silber S, et al. Randomized study to assess the effectiveness of slow- and moderate-release polymer-based paclitaxel-eluting stents for coronary artery lesions. Circulation 2003;108:788-94

20 Stone GW, Ellis SG, Cox DA, Hermiller J, O'Shaughnessy C, Mann JT, et al. A polymer-based, paclitaxel-eluting stent in patients with coronary artery disease. N Engl $J$ Med 2004;350:221-31.

21 Eisenstein EL, Anstrom KJ, Kong DF, Shaw LK, Tuttle RH, Mark DB, et al. Clopidogrel use and long-term clinical outcomes after drug-eluting stent implantation. JAMA 2007;297:159-68. 


\section{What is already known on this topic}

Biodegradable polymer drug eluting stents were developed to preserve the safety of bare metal stents while maintaining the efficacy (reduction of restenosis) of durable polymer drug eluting stents

The efficacy and safety of biodegradable polymer stents compared with newer generation durable polymer stents, which have been shown to be as safe as or safer than bare metal stents, is not known

\section{What this study adds}

Biodegradable polymer drug eluting stents are superior to first generation durable polymer drug eluting stents in reducing restenosis, but not to newer generation durable polymer stents

Newer generation durable polymer stents, and especially the cobalt chromium everolimus eluting stent, have the best combination of efficacy and safety

The utility of biodegradable polymer stents in the context of excellent clinical outcomes with newer generation durable polymer drug eluting stents needs to be proven

McFadden EP, Stabile E, Regar E, Cheneau E, Ong AT, Kinnaird T, et al. Late thrombosis in drug-eluting coronary stents after discontinuation of antiplatelet therapy. Lancet 2004;364:1519-21.

23 Virmani R, Guagliumi G, Farb A, Musumeci G, Grieco N, Motta T, et al. Localized hypersensitivity and late coronary thrombosis secondary to a sirolimus-eluting stent: should we be cautious? Circulation 2004;109:701-5.

24 Stefanini GG, Byrne RA, Serruys PW, de Waha A, Meier B, Massberg S, et al. Biodegradable polymer drug-eluting stents reduce the risk of stent thrombosis at 4 years in patients undergoing percutaneous coronary intervention: a pooled analysis of individual patient data from the ISAR-TEST 3, ISAR TEST 4, and LADERS randomized trials. Eur Heart J2012:33:1214-22.

25 Sarno G, Lagerqvist B, Frobert O, Nilsson J, Olivecrona O, Omerovic E, et al. Considerably lower risk of stent thrombosis and restenosis in "new generation" drug-eluting stents: a report from the nation wide complete Swedish Coronary Angiography and Angioplasty Registry (SCAAR) [abstract]. Eur Heart J 2011;32:509.

26 Valgimigli M, Campo G, Monti M, Vranckx P, Percoco G. Tumscitz C, et al. Short- versus long-term duration of dual-antiplatelet therapy after coronary stenting: a randomized multicenter trial. Circulation 2012;125:2015-26.
27 Kereiakes DJ, Popma JJ, Cannon LA, Kandzari DE, Kimmelstiel CD, Meredith IT, et al. Longitudinal stent deformation: quantitative coronary angiographic analysis from the PERSEUS and PLATINUM randomised controlled clinical trials. Eurolntervention 2012;8:187-95.

Accepted: 22 October 2013

\section{Cite this as: BMJ 2013;347:f6625}

This is an Open Access article distributed in accordance with the Creative Commons Attribution Non Commercial (CC BY-NC 3.0) license, which permits others to distribute, remix, adapt, build upon this work non-commercially, and license their derivative works on different terms, provided the original work is properly cited and the use is non-commercial. See: http://creativecommons.org/licenses/by-nc/3.0/. 


\section{Tables}

Table 1 | Select definitions of efficacy and safety outcomes used in the study ${ }^{8}$

Outcomes

Definition

\section{Efficacy}

Target vessel revascularization Any repeat percutaneous intervention or surgical bypass of any segment of target vessel. Target vessel is defined as entire major coronary vessel proximal and distal to target lesion, which includes upstream and downstream branches and target lesion itself

Target lesion revascularization Any repeat percutaneous intervention of target lesion or bypass surgery of target vessel performed for restenosis or other complication of target lesion. Target lesion is defined as treated segment from $5 \mathrm{~mm}$ proximal to stent to $5 \mathrm{~mm}$ distal to stent

\section{Safety}

Definite stent thrombosis Angiographic or pathological confirmation of stent thrombosis

Probable stent thrombosis Any unexplained death within first 30 days or irrespective of time after the index procedure; any myocardial infarction that is related to documented acute ischemia in territory of implanted stent without angiographic confirmation of stent thrombosis and in absence of any other obvious cause 
Table 2/ Median rate (per 100 patient years of follow-up) of selected efficacy and safety outcomes and probability that each stent type has lowest event rate, from mixed treatment comparison analysis of all available trials in network

\begin{tabular}{lcccccccc} 
Stent type & TVR rate (95\% Crl) & $\begin{array}{c}\text { Probability } \\
\text { best (\%) }\end{array}$ & Death rate (95\% Crl) & $\begin{array}{c}\text { Probability } \\
\text { best (\%) }\end{array}$ & MI rate (95\% Crl) & $\begin{array}{c}\text { Probability } \\
\text { best (\%) }\end{array}$ & $\begin{array}{c}\text { ARC definite ST } \\
\text { (95\% Crl) }\end{array}$ & $\begin{array}{c}\text { Probability } \\
\text { best (\%) }\end{array}$ \\
\hline Bare metal & $8.06(7.41$ to 8.69$)$ & 0 & $2.11(1.79$ to 2.54$)$ & 0 & $1.88(1.54$ to 2.30$)$ & 0 & $0.39(0.25$ to 0.60$)$ & 0 \\
\hline Sirolimus & $3.61(32.25$ to 40.03$)$ & 0 & $1.82(1.51$ to 2.19$)$ & 0 & $1.56(1.26$ to 1.92$)$ & 0 & $0.39(0.25$ to 0.62$)$ & 0 \\
\hline Paclitaxel & $4.97(4.41$ to 5.57$)$ & 0 & $1.87(1.52$ to 2.27$)$ & 0 & $1.84(1.48$ to 2.26$)$ & 0 & $0.46(0.29$ to 0.75$)$ & 0 \\
\hline CoCr-everolimus & $3.21(2.73$ to 3.68$)$ & 9 & $1.52(1.20$ to 1.91$)$ & 18 & $1.22(0.96$ to 1.55$)$ & 29 & $0.13(0.07$ to 0.24$)$ & 81 \\
\hline PtCr-everolimus & $2.95(2.06$ to 4.17$)$ & 50 & $1.51(0.99$ to 2.30$)$ & 31 & $1.15(0.79$ to 1.72$)$ & 56 & $0.19(0.07$ to 0.50$)$ & 17 \\
\hline Zotarolimus-E & $4.75(4.07$ to 5.63$)$ & 0 & $1.84(1.37$ to 2.45$)$ & 2 & $1.52(1.18$ to 1.94$)$ & 0 & $0.30(0.17$ to 0.57$)$ & 0 \\
\hline Zotarolimus-R & $3.08(2.26$ to 3.98$)$ & 30 & $1.46(0.97$ to 2.26$)$ & 40 & $1.34(0.98$ to 1.86$)$ & 12 & $0.34(0.13$ to 0.82$)$ & 0 \\
\hline $\begin{array}{l}\text { Biodegradable } \\
\text { polymer }\end{array}$ & $3.30(2.79$ to 3.87$)$ & 9 & $1.70(1.31$ to 2.21$)$ & 6 & $1.51(1.16$ to 1.93$)$ & 0 & $0.28(0.16$ to 0.48$)$ & 0 \\
\hline
\end{tabular}

Rates are per 100 patient years of follow-up using Bayesian Markov Chain Monte Carlo (MCMC) method.

$\mathrm{ARC}=\mathrm{Academic}$ Research Consortium; $\mathrm{CoCr}=$ cobalt chromium; Crl=credibility interval; $\mathrm{Ml}=$ myocardial infarction; $\mathrm{PtCr}=$ platinum chromium; ST=stent thrombosis; TVR=target vessel revascularization. 
Table 3| Median rate (per 100 patient years of follow-up) of selected efficacy and safety outcomes in landmark analysis beyond one year and probability that each stent type has lowest event rate from mixed treatment comparison analysis of all available trials in network

\begin{tabular}{|c|c|c|c|c|c|c|c|c|}
\hline Stent type & Death rate $(95 \% \mathrm{Crl})$ & $\begin{array}{c}\text { Probability } \\
\text { best (\%) }\end{array}$ & MI rate $(95 \% \mathrm{Crl})$ & $\begin{array}{c}\text { Probability } \\
\text { best (\%) }\end{array}$ & $\begin{array}{c}\text { ARC definite ST } \\
\text { (95\% Crl) }\end{array}$ & $\begin{array}{c}\text { Probability } \\
\text { best (\%) }\end{array}$ & TVR (95\% Crl) & $\begin{array}{c}\text { Probability } \\
\text { best (\%) }\end{array}$ \\
\hline Bare metal & 0.88 (0.69 to 1.07 ) & 0 & 0.28 ( 0.18 to 0.43 ) & 0 & 0.02 (0.01 to 0.05$)$ & 1 & $1.57(1.36$ to 1.80$)$ & 0 \\
\hline Sirolimus & 0.84 (0.65 to 1.04 ) & 0 & 0.33 (0.21 to 0.51$)$ & 0 & $0.08(0.03$ to 0.19$)$ & 0 & 1.34 (1.07 to 1.64$)$ & 0 \\
\hline Paclitaxel & 0.75 (0.58 to 0.96$)$ & 0 & 0.35 (0.21 to 0.57$)$ & 0 & 0.04 (0.02 to 0.11$)$ & 0 & 1.32 (1.04 to 1.69$)$ & 0 \\
\hline CoCr-everolimus & $0.48(0.35$ to 0.68$)$ & 13 & 0.21 ( 0.12 to 0.36 ) & 21 & 0.01 (0.00 to 0.04 ) & 23 & 0.92 (0.63 to 1.28$)$ & 9 \\
\hline PtCr-everolimus & $0.36(0.18$ to 0.76$)$ & 73 & 0.30 (0.09 to 1.14$)$ & 17 & $0.02(0.00$ to 0.16$)$ & 17 & $0.70(0.29$ to 1.60$)$ & 66 \\
\hline Zotarolimus-E & 0.73 (0.53 to 0.97 ) & 0 & 0.26 (0.14 to 0.45$)$ & 5 & 0.01 (0.00 to 0.05 ) & 16 & 1.09 (0.78 to 1.52$)$ & 4 \\
\hline Zotarolimus-R & 0.58 (0.32 to 1.01$)$ & 12 & 0.24 (0.09 to 0.57 ) & 26 & 0.01 (0.00 to 0.10$)$ & 32 & 1.03 (0.53 to 1.85$)$ & 12 \\
\hline $\begin{array}{l}\text { Biodegradable } \\
\text { polymer }\end{array}$ & 0.74 (0.53 to 1.03 ) & 0 & 0.22 (0.12 to 0.42$)$ & 28 & 0.02 (0.00 to 0.08$)$ & 7 & 1.05 (0.71 to 1.46$)$ & 6 \\
\hline
\end{tabular}

Rates are per 100 patient years of follow-up using Bayesian Markov Chain Monte Carlo method.

$\mathrm{CoCr}=$ cobalt chromium; $\mathrm{Crl}=$ credibility interval; $\mathrm{Ml}=$ myocardial infarction; $\mathrm{PtCr}=$ platinum chromium; $\mathrm{ST}=$ stent thrombosis; TVR=target vessel revascularization. 


\section{Figures}

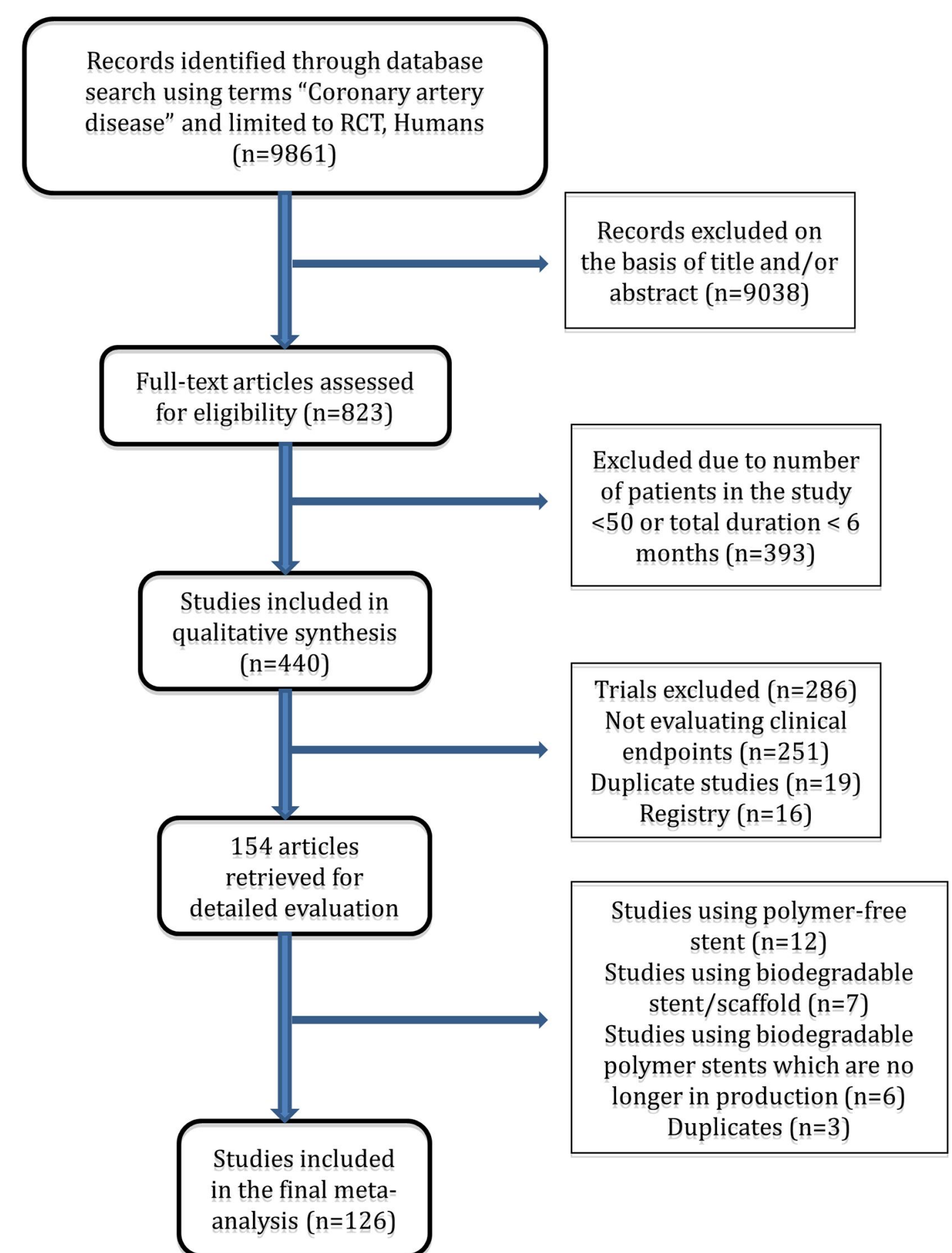

Fig 1 Flow chart of study selection 


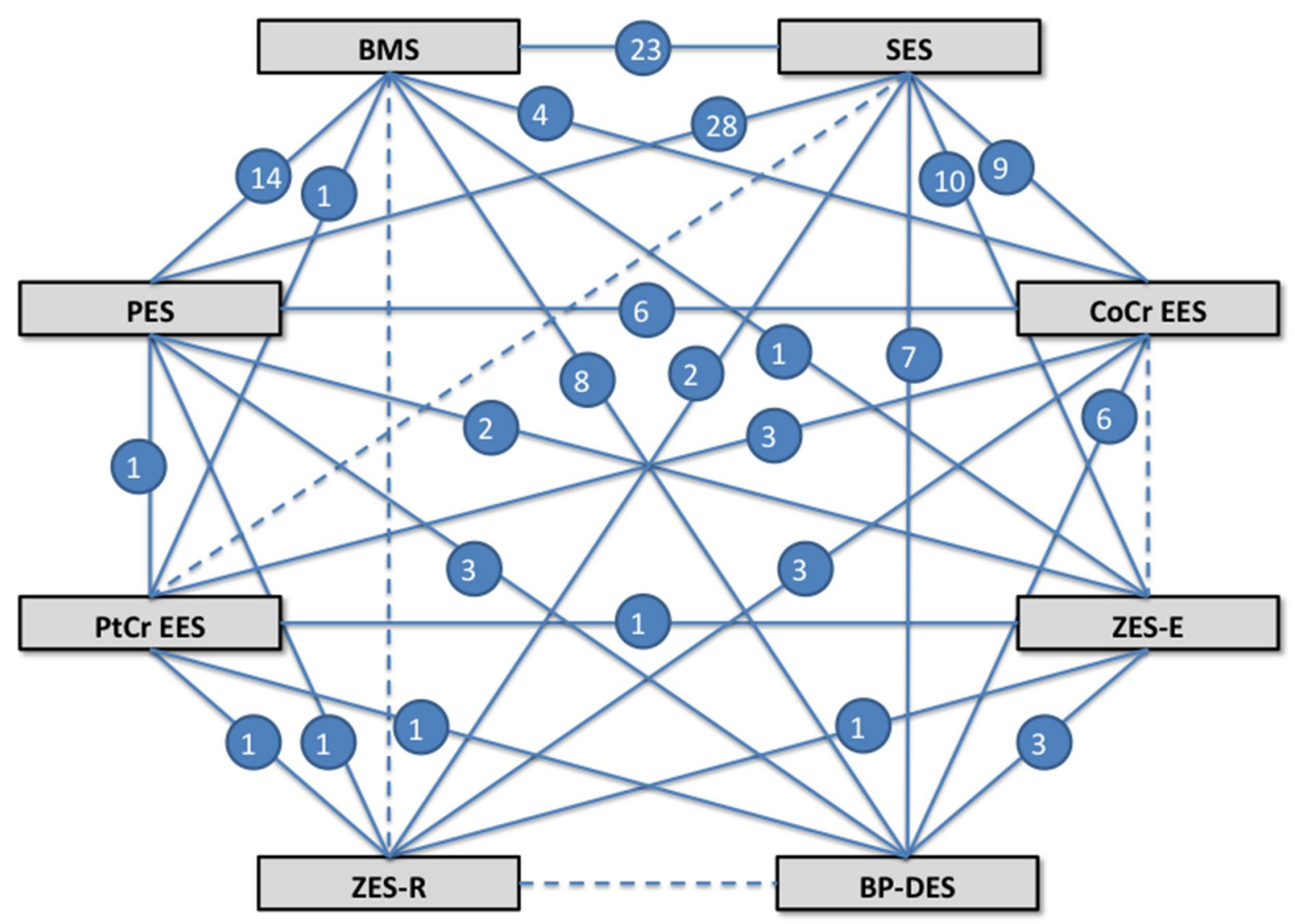

Fig 2 Network of treatment comparisons. Solid line represents direct comparison between stents; dashed line represents indirect comparison between stent types; number represents number of trial providing direct comparison. BMS=bare metal stent; BP-DES=biodegradable polymer stent; $\mathrm{CoCr}=$ cobalt chromium; EES=everolimus eluting stent; $P E S=$ paclitaxel eluting stent; $\mathrm{PtCr}=$ platinum chromium; SES=sirolimus eluting stent; ZES-E=zotarolimus eluting stent-Endeavor; ZES-R=zotarolimuS eluting stent-Resolute 
Outcome: TVR

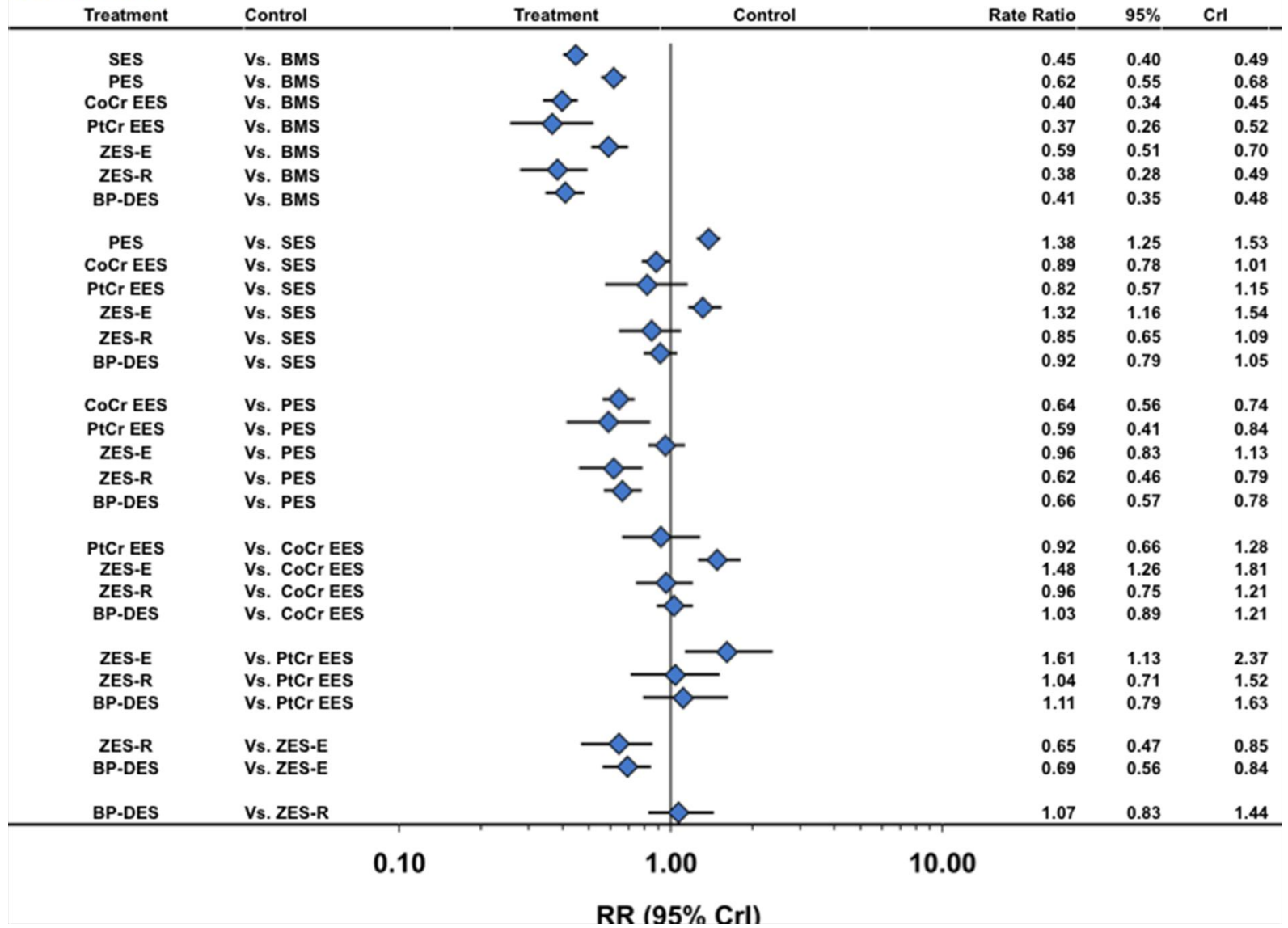

Fig 3 Stent type and risk of target vessel revascularization from network of all trials. Crl=credibility interval; other abbreviations as in fig 1 


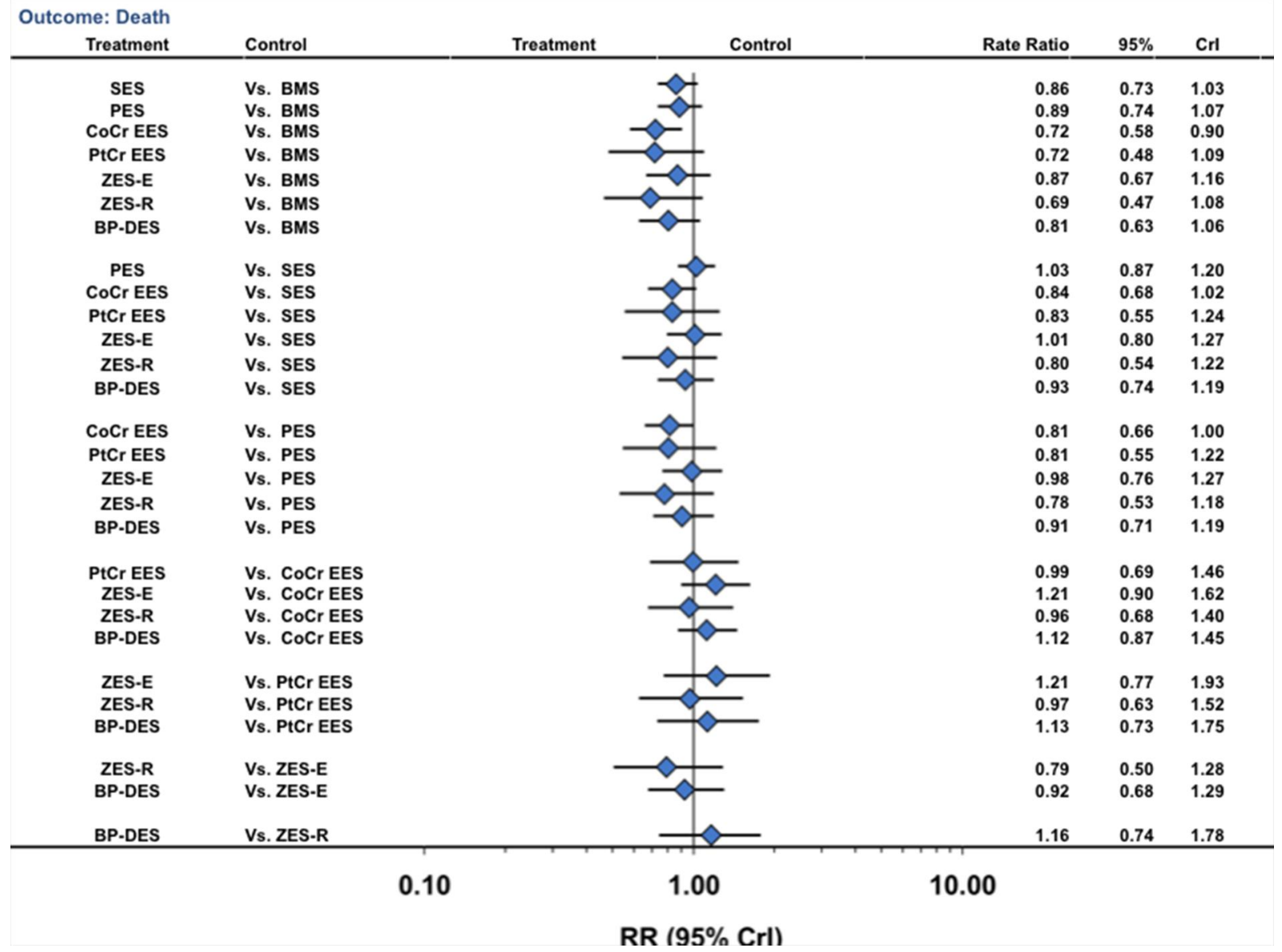

Fig 4 Stent type and risk of death from network of all trials. Crl=credibility interval; other abbreviations as in figure 1 


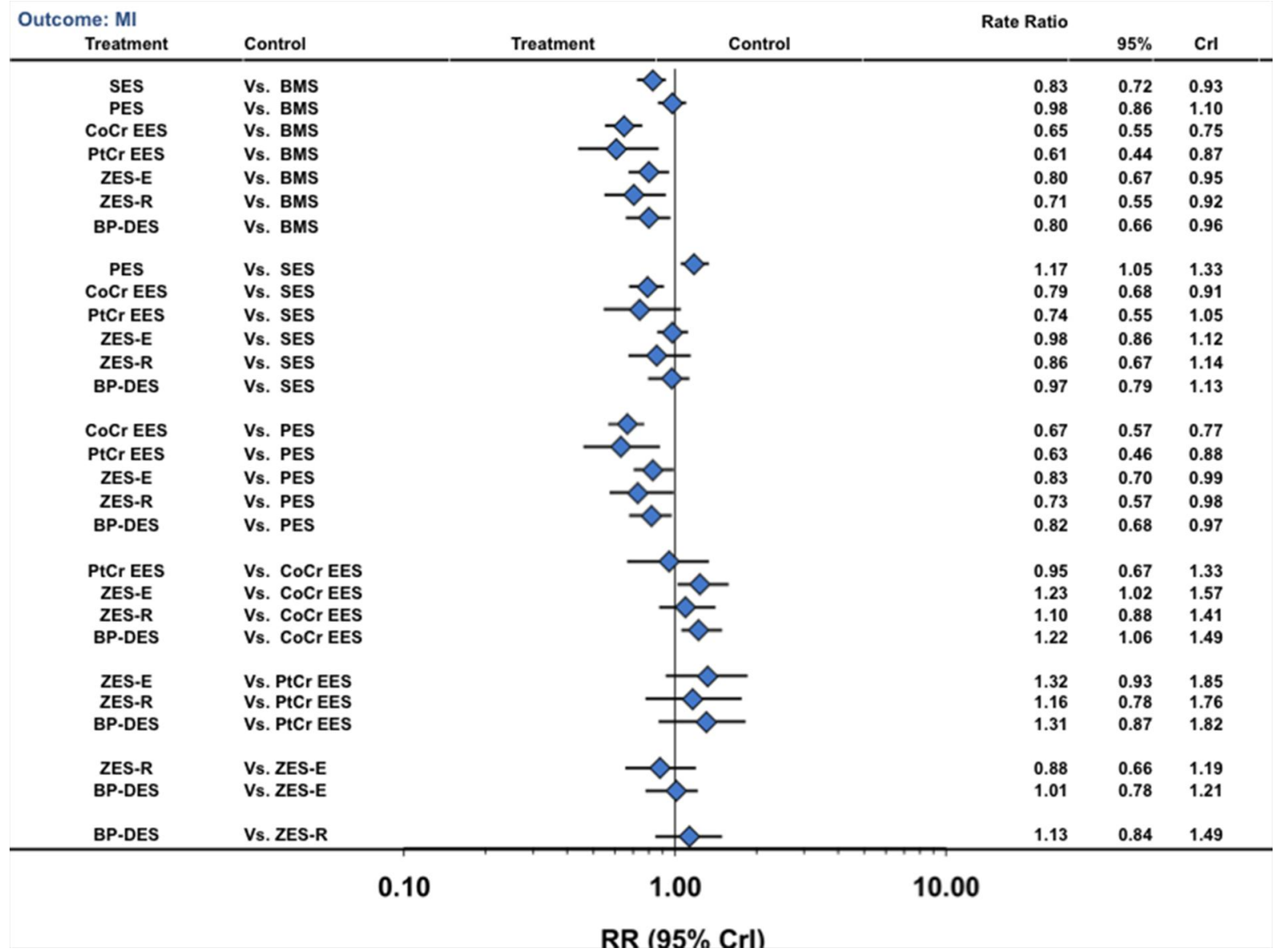

Fig 5 Stent type and risk of myocardial infarction from network of all trials. Crl=credibility interval; other abbreviations as in figure 1 
Outcome: Definite ST

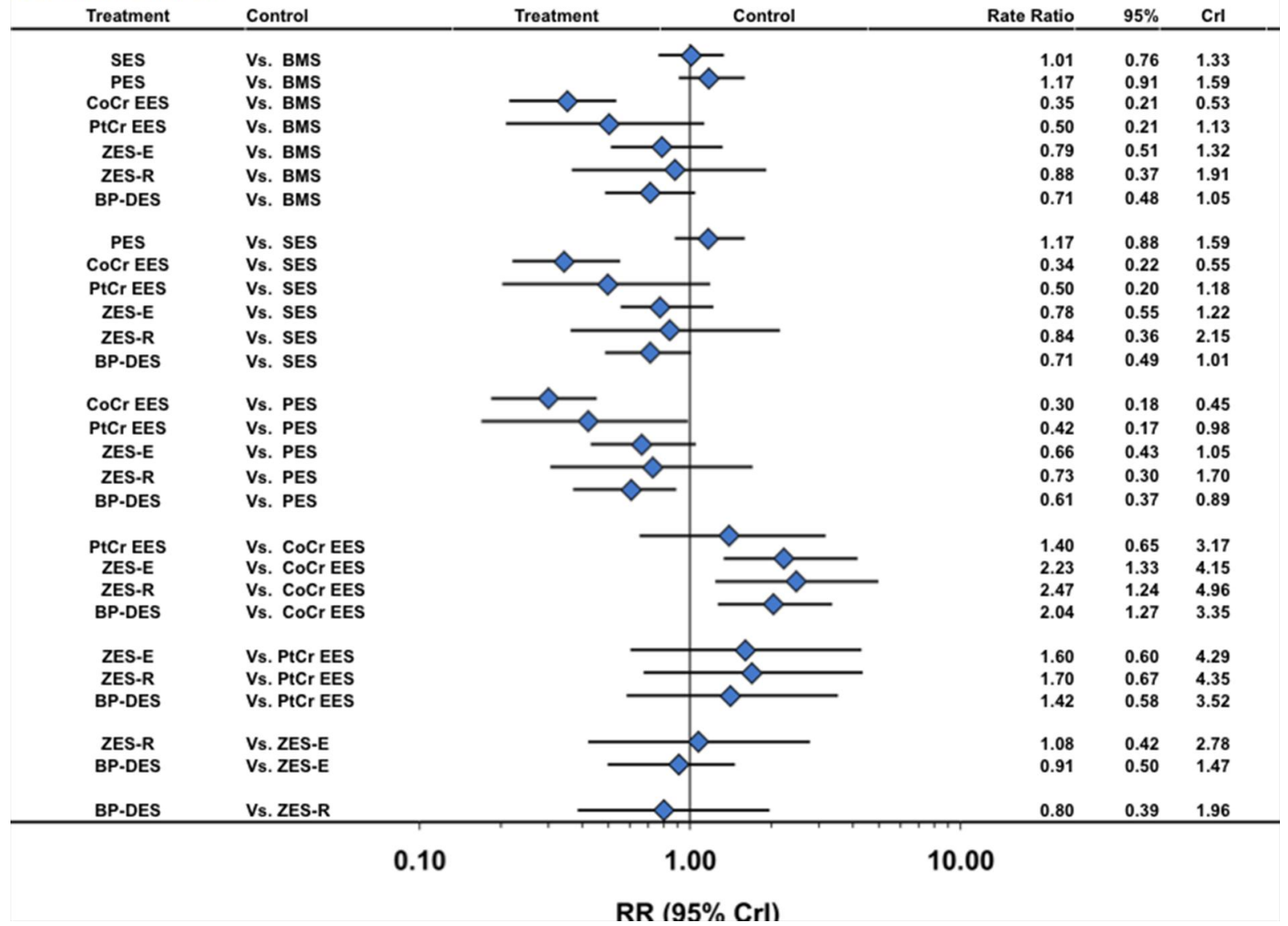

Fig 6 Stent type and risk of Academic Research Consortium defined definite stent thrombosis from network of all trials. Crl=credibility interval; other abbreviations as in figure 1 
Outcome: TVR

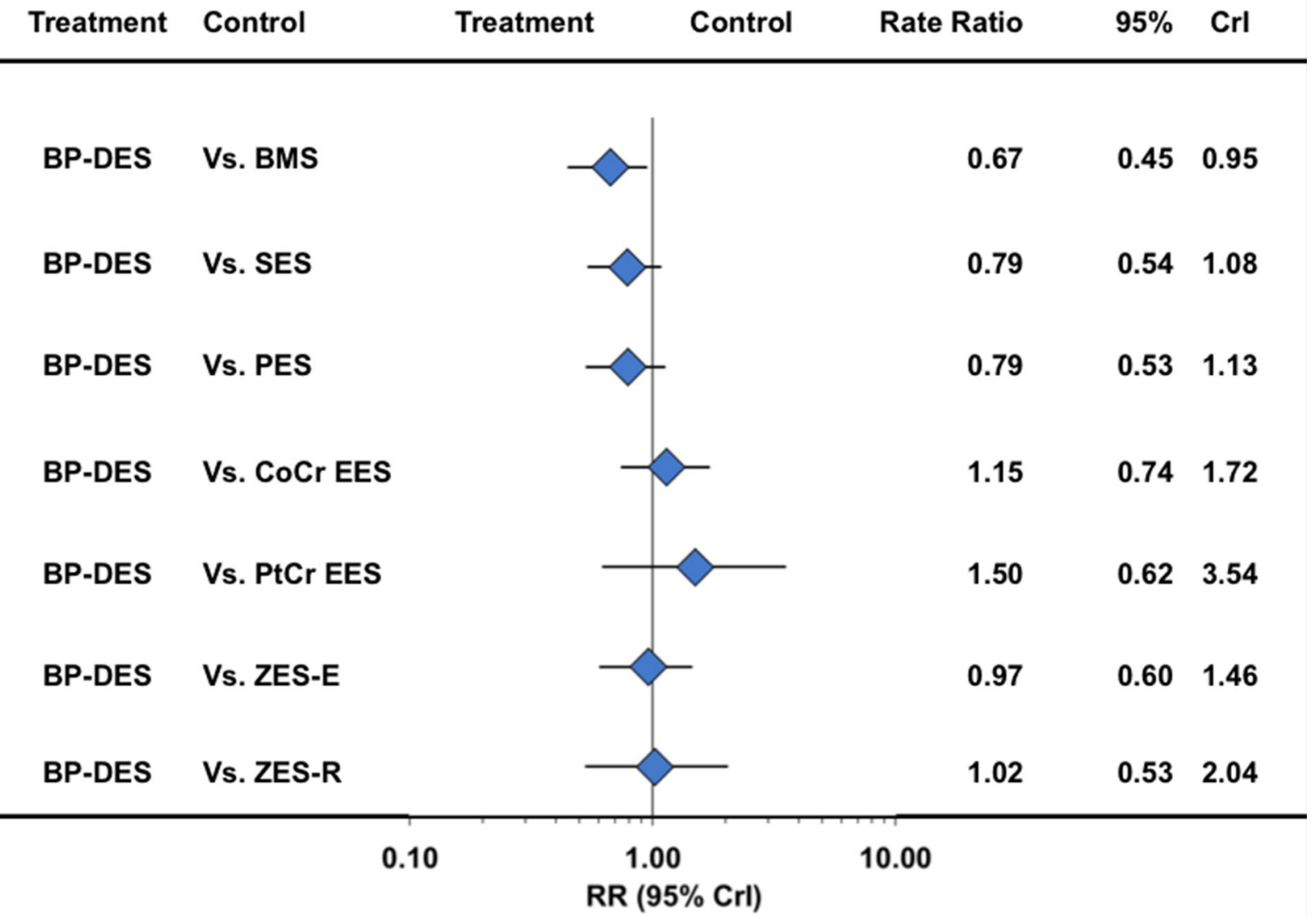

Fig 7 Biodegradable polymer stents in comparison with other stents and risk of target vessel revascularization from network of all trials in landmark analysis beyond one year. Crl=credibility interval; other abbreviations as in figure 1 


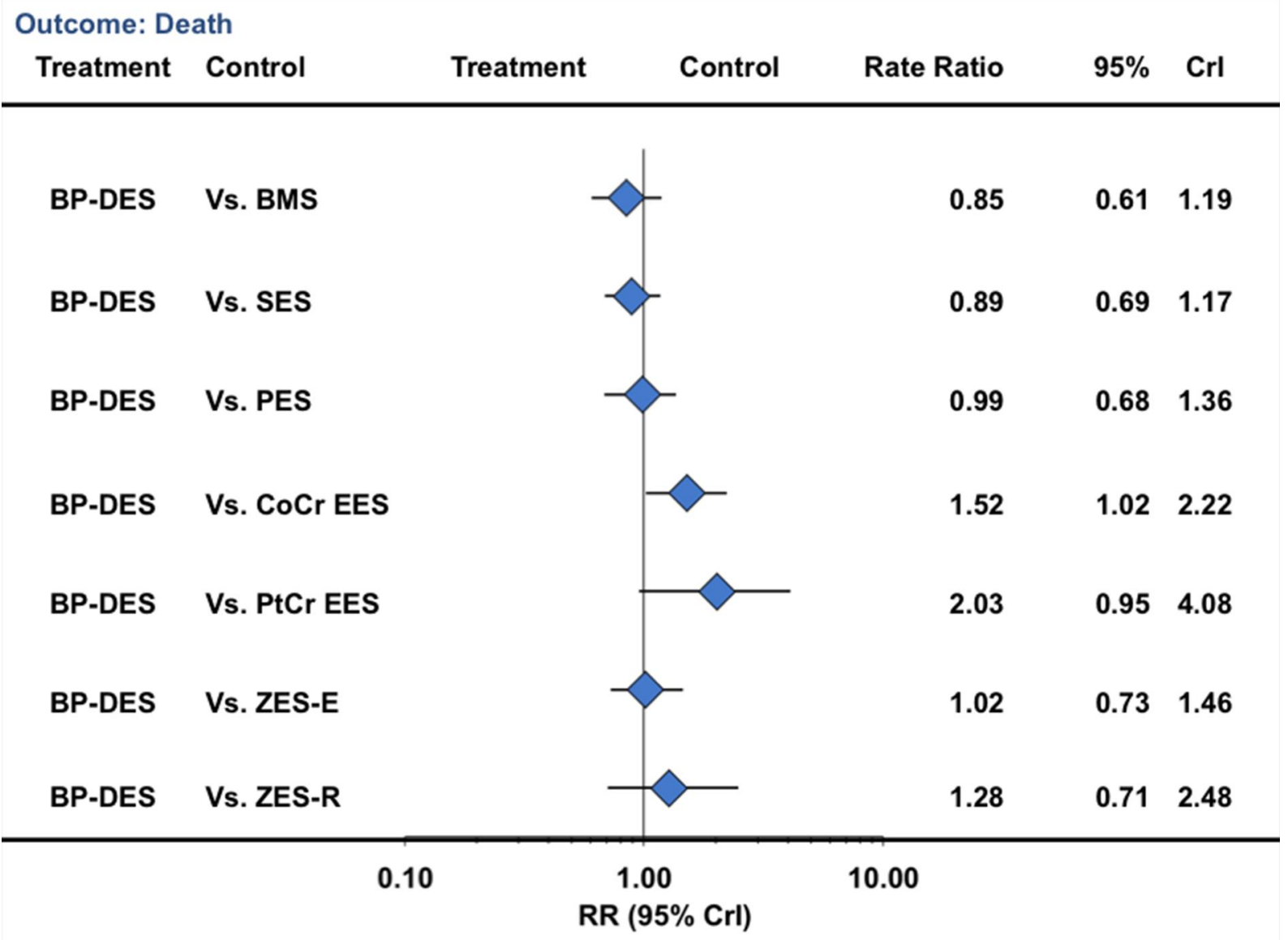

Fig 8 Biodegradable polymer stents in comparison with other stents and risk of death from network of all trials in landmark analysis beyond one year. $\mathrm{Crl}=$ credibility interval; other abbreviations as in figure 1 


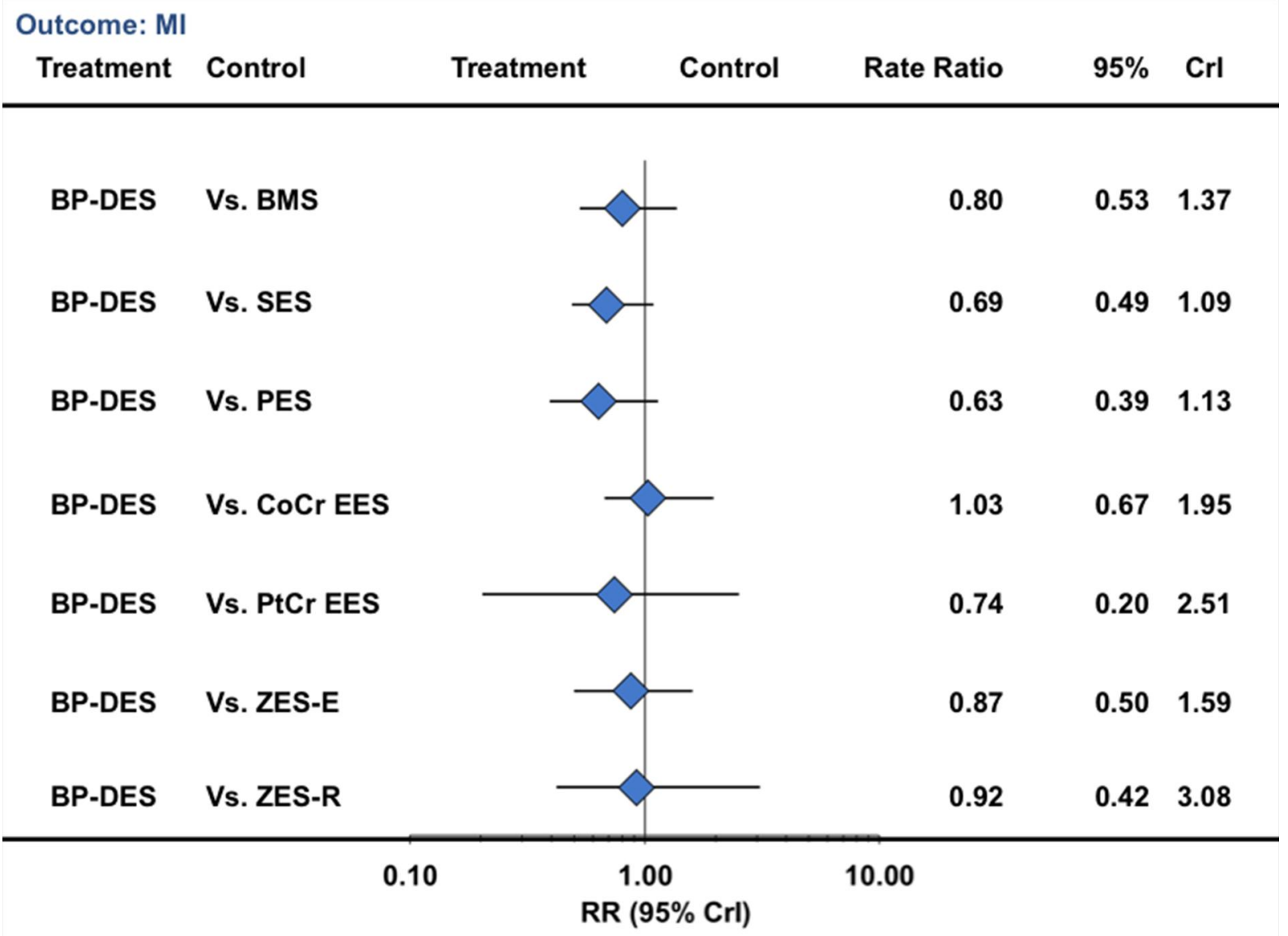

Fig 9 Biodegradable polymer stents in comparison with other stents and risk of myocardial infarction from network of all trials in landmark analysis beyond one year. $\mathrm{Crl}=$ credibility interval; other abbreviations as in figure 1 
Outcome: Definite ST

Treatment Control

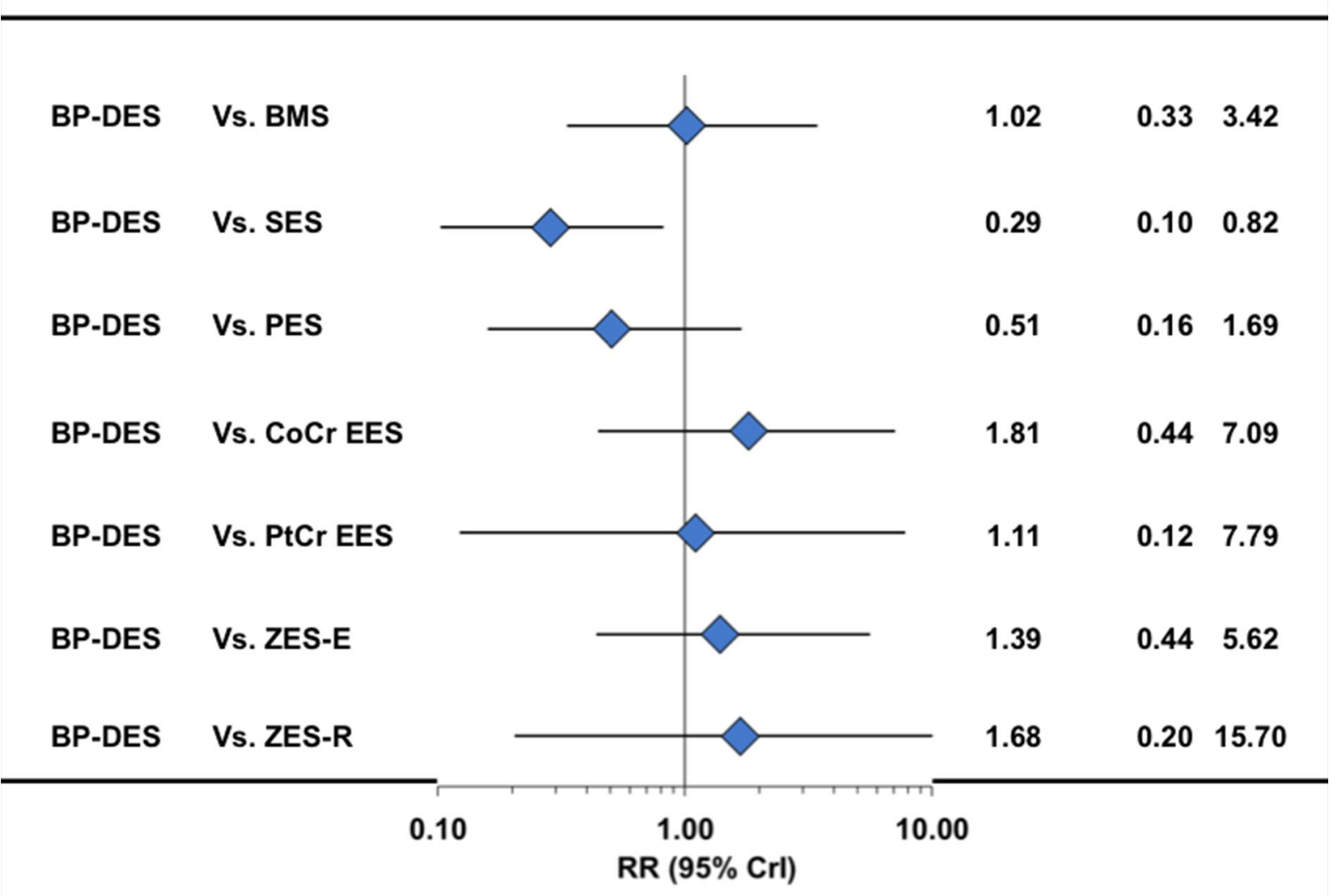

Fig 10 Biodegradable polymer stents in comparison with other stents and risk of Academic Research Consortium defined definite stent thrombosis from network of all trials in landmark analysis beyond one year. Crl=credibility interval; other abbreviations as in figure 1 